
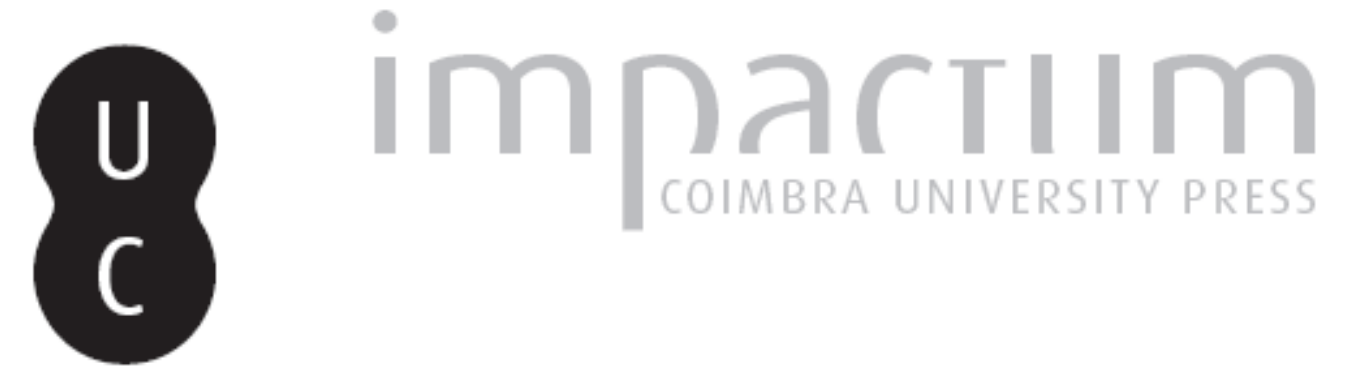

\title{
O recurso a pessoal estrangeiro no tempo de Pombal
}

\author{
Autor(es): $\quad$ Carvalho, Rómulo de
}

Publicado por: Imprensa da Universidade de Coimbra

URL persistente:

URl:http://hdl.handle.net/10316.2/43861

DOI:

DOI:https://doi.org/10.14195/2183-8925_4-1_5

Accessed : $\quad$ 26-Apr-2023 11:04:29

A navegação consulta e descarregamento dos títulos inseridos nas Bibliotecas Digitais UC Digitalis, UC Pombalina e UC Impactum, pressupõem a aceitação plena e sem reservas dos Termos e Condições de Uso destas Bibliotecas Digitais, disponíveis em https://digitalis.uc.pt/pt-pt/termos.

Conforme exposto nos referidos Termos e Condições de Uso, o descarregamento de títulos de acesso restrito requer uma licença válida de autorização devendo o utilizador aceder ao(s) documento(s) a partir de um endereço de IP da instituição detentora da supramencionada licença.

Ao utilizador é apenas permitido o descarregamento para uso pessoal, pelo que o emprego do(s) título(s) descarregado(s) para outro fim, designadamente comercial, carece de autorização do respetivo autor ou editor da obra.

Na medida em que todas as obras da UC Digitalis se encontram protegidas pelo Código do Direito de Autor e Direitos Conexos e demais legislação aplicável, toda a cópia, parcial ou total, deste documento, nos casos em que é legalmente admitida, deverá conter ou fazer-se acompanhar por este aviso.

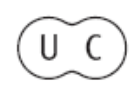




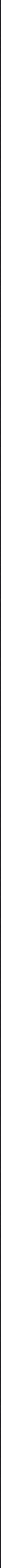


RÓMULO DE CARVAIHO:

\section{O RECURSO A PESSOAL ESTRANGEIRO NO TEMPO DE POMBAL}

Decorridos apenas dois dias sobre o falecimento de D. João V, já o seu sucessor, D. José, determinara quais as personalidades que iriam constituir o elenco ministerial com que daria início à sua governação. Não se tratava de simples acto rotineiro, mas de uma acção ponderada com vista a conseguir-se que a nação portuguesa, dirigida por novas mentalidades, dinâmicas e esclarecidas, se encaminhasse por uma via de aproximação dos países europeus mais evoluídos. Já nos últimos anos de vida do rei defunto, em que este, paralítico e moralmente abatido, se alheara da actividade governativa posta nas mãos de homens caducos e improdutivos, algumas vozes respeitadas se faziam ouvir acentuando o nosso atraso em todos os domínios, subjugados pela tirania infamante do Santo Ofício, pelo poder imobilizador da Igreja, pela exploração abusiva da classe aristocrática, sem comércio nem indústrias relevantes, sem desenvolvimento agrícola, sem estradas nem transportes, sem exército nem marinha. A época joanina tivera grande notoriedade no incremento das artes, no cultivo das letras, na sumptuosidade das construções, mas deixara o país carecido das condições mínimas para proporcionar um progresso real à sua população. Uma daquelas vozes respeitadas era a de D. Luís da Cunha, diplomata com quarenta anos de carreira contínua em países europeus evo luídos, colocado em condições excelentes para comparar o nosso atraso material, o nosso acanhamento mental e o obscurantismo a que éramos sujeitos, com o progresso constantemente fomentado nesses países e a liberdade de expressão neles consentida, a qual, embora sujeita a limitações, era infini-

* Professor aposentado do Ensino Secundário, e Investigador. 


\section{O Marquês de Pombal}

tamente superior à nossa. Nas palavras que o diplomata nos legou no corajoso texto do seu Testamento Político acentuam-se, com firmeza e vivacidade, diversos aspectos da nossa baixa condição social. E o que se vê, por exemplo, neste passo em que D. Luís da Cunha convida D. José, então ainda príncipe, $\epsilon$ a quem o Testamento é dirigido, a dar uma volta pelo reino para apreciar o que nele se passava: «Achará, não sem espanto, muitas terras usurpadas ao comum, outras incultas, muitíssimos caminhos impraticáveis, de que resulta faltar o que elas podiam produzir, e não haver entre as províncias a comunicação necessária para o seu comércio: achará muitas e grandes povoações quase desertas, com as suas manufacturas arruinadas, perdidas, e extinto totalmente o seu comércio: achará que a terça parte de Portugal está possuída pela Igreja, que não contribui para a despesa e segurança do Estado, quero dizer, pelos cabidos das dioceses, pelas colegiadas, pelos priorados, pelas abadias, pelas capelas, pelos conventos de frades e freiras» $[\ldots]\left({ }^{1}\right)$.

Mostrou-se o novo rei, D. José, consciente do estado precário da nação nas suas diversas actividades, e dessa consciência lhe teria nascido a determinação de se rodear de colaboradores capazes de realizarem a transformação social que as circunstâncias exigiam. D. Luís da Cunha, no Testamento Político, já tinha sugerido ao príncipe de então, agora rei, alguns nomes de personalidades que admitia estarem à altura das circunstâncias, e um deles foi o de Sebastião José de Carvalho e Melo, "cujo génio paciente, especulativo e ainda que sem vício, um pouco difuso, se acorda com o da nação» $\left({ }^{2}\right)$. D. José aceitou o alvitre.

Ainda em tempo de D. João V estivera Carvalho e Melo $\left(^{3}\right)$ cerca de seis anos em Londres, em missão diplomática da corte portuguesa, e aí tivera oportunidade de apreciar $o$ progresso da sociedade inglesa e de comparar a agitação de um grande país trabalhador, afanosamente aplicado ao comércio e à indústria, com o seu país natal. Dessa estada colheu informações que a sua mente política foi utilizando na construção de projectos que algum dia, se o futuro o permitisse, o ajudariam a resolver a situação portuguesa. Muito aí apren-

(i) D. Luís da Cunha, Testamento Político, Lisboa, 1943, pp. 39-40.

(') D. Luís da Cunha, ob. cit, p. 26.

(') Por hábito consagrado designaremos muitas vezes Sebastião José de Carvalho e Melo por «marquès de Pombal» ou somente «Pombal», embora nem sempre a designação corresponda a épocas da sua vida em que já possuía esse título. 
deu, sem dúvida, mas escapou-lhe um pormenor que alguns estudiosos da acção governativa do marquês de Pombal já puseram em evidência. $\mathbf{O}$ homem de Estado não percebeu que o êxito da prosperidade da vida inglesa provinha da liberdade do seu povo e pretendeu alcançar os mesmos resultados para Portugal por via da violência $\left({ }^{4}\right)$.

Um pequeno episódio ocorrido durante a enviatura de Carvalho e Melo em Londres põe bem em confronto a sua men. talidade repressiva e autoritária com a do meio em que então vivia. Francisco Xavier de Oliveira, o "Cavaleiro de Oliveira". procurou ser recebido por Carvalho e Melo, em Londres, e conseguiu-o ao fim de muita insistência. Relatando a conversa, escrevia o futuro marquês de Pombal para Marco António de Azevedo Coutinho: "VEx." sabe que eu não dezejo fazer mal; mas intendo $\mathrm{q}$ he gr. $\mathrm{d}^{\mathrm{e}}$ bem metter este homem em huã prisão, se p." isso houver meyo". E acrescentava, com desolação: "VEx." sabe porem qual he a constituiçaõ deste Pays" $\left({ }^{8}\right)$. Quando Carvalho e Melo, em 1750, ascendeu ao cargo de ministro da pasta do Reino, teria feito o balanço de todos os dados recolhidos nas suas permanências no estrangeiro, primeiro em Londres e depois em Viena de Austria, e com eles esboçado os projectos que lhe pareceram mais próprios para a reforma da nação. Sopesou decerto as potencialidades portuguesas e teria concluído que não poderia contar muito com elas. 0 remédio seria recorrer ao estrangeiro, receber de fora os homens actuantes, profissionalmente bem preparados, conscientes e empreendedores, e transferir deles para as nossas veias o sangue que nos daria a vitalidade de que carecíamos, isto, é claro, sem alterar em nada a nossa mentalidade de cidadãos obedientes e resignados, que continuariam a ter nos aur tos-de-fé públicos os seus encontros e distracções colectivas.

(4) Por exemplo Lúcio de Azevedo em $O$ marquês de Pombal e a sua época, Lisboa, 1909. O exemplo da Inglaterra como defensora da liberdade dos cidadãos não era caso único na Europa. Colhemos um apontamento numa carta escrita por Luís da Cunha Manuel, sobrinho de D. Luís da Cunha, dirigida ao nosso cônsul na Holanda, Domingos Luís da Costa, com data de 26-VI-1768, em plena ditadura pombalina, em que Cunha Manuel, a propósito de certo assunto que está tratando, diz «Nesse Paiz hé livre o falar, e assim vm.` alguma couza hade ouvir». interessante acrescentar que Cunha Manuel era membro do Governo de então, e um dos braços executantes das determinaçōes de Pombal, a quem obedecia cegamente (Torre do Tombo, Papéis de Mendonça Corte-Real que vieram do Conselho de Guerra, Março 296, macete $\mathrm{g}$ ).

(") Torre do Tombo, Minist, dos Neg. Estrang., Legação de Portugal em Londres, Caixa A, ofício de 23-III-1745. 


\section{O Marquês de Pombal}

Não seria fácil dizer a qual das carências nacionais deveria ser dada prioridade na tentativa da sua resolução. Aliás algumas dessas carências, pela sua própria natureza, iriam tomando maior vulto à medida que fossem criadas determinadas situações, como sucedeu com a deflagração da guerra com a Espanha que pôs em relevo a incapacidade do exército que então tínhamos, e com a expulsão da Companhia de Jesus que pôs a descoberto a desactualização do nosso ensino. Uma carência sentida no dia a dia, com gravíssima repercussão na economia do país, era a falta de dimensão mínima adequada das nossas indústrias. Surpreende que, após a descoberta das opulentíssimas riquezas minerais do solo brasileiro, transportadas para este pequeno rectângulo europeu durante a governação de D. João V, nos encontrássemos, poucos anos decorridos, a braços com a miséria. Deparava-se então a Portugal - diz um dos historiadores da nossa economia - «um novo agente, que aumentando prodigiosamente o nosso capital, devia pôr a nova indústria na maior actividade. Este agente era o ouro das minas do Brasil, que se descobriram por esse tempo e pouco depois as dos diamantes; porém correndo atrás desta riqueza de convenção, desprezámos os nossos bens reais; o reino despovoou-se e Portugal, nadando em ouro, viu-se pobre quando lhe foi preciso entregar este mesmo ouro à Inglaterra, e às outras naçōes industriosas para nutrir e vestir os seus próprios habitantes com géneros de produção estrangeira, negociados por estrangeiros e conduzidos em embarcaçōes estrangeiras" $\left({ }^{6}\right)$.

Era grande, de facto, o número de comerciantes de outros países que vinham instalar-se em Portugal, particularmente em Lisboa, aproveitando-se das óptimas condições que, para eles, o país lhes proporcionava. Quase todos os bens eram importados, mesmo aqueles que modestas oficinas nacionais poderiam fabricar. Seria necessário criar centros de produção ou incentivar os que já existissem para alcançarem maior produtividade, de qualidade superior, melhorar a mão de obra educando o operário, conquistar a sua adesão consciente a um plano de modernização do país. Muitas dificuldades se levantavam a tal projecto, agravadas com a ideia, ainda hoje tão radicada no espírito dos portugueses, de que só os produtos estrangeiros têm qualidade, e de que nunca seríamos capazes de igualá-los. Um francês, Jácome Ratton, que viveu entre nós toda a segunda metade do século XVIII (e ainda parte do sé-

(') José Acúrsio das Neves, Noções históricas, económicas e administrativas, etc., Lisboa, 1827, p. 23. 
culo XIX), exercendo actividades industriais, teve oportunidade de conhecer em pormenor, e intimamente, a vida portuguesa no que se relacionava com a sua ocupação profissional. Da obra que escreveu já no fim da vida recordando o passado, recolhem-se informaçồes valiosas como esta: «O pouco conhecimento, que havia então de fábricas, e o desprezo, que havia pela palavra fabricante, confundida com manipulador, official, obreiro, operário, \&c.; assim como também imaginarem que taes estabelecimentos» [as fábricas] "não podiaõ vingar em Portugal, ideas que os estrangeiros ali estabelecidos naõ cessavaõ de suggerir, para bem dos seus interesses» dificultaram os seus projectos pessoais $\left({ }^{7}\right)$.

Carvalho e Melo gizou um plano de desenvolvimento industrial que consistiu na criação de grande número de fábricas, consagradas ao fabrico de produtos diversos, mandando vir, do estrangeiro, para todas elas, mestres habilitados nas respectivas artes que, por contrato, se obrigassem a instruir - pessoal português dessas fábricas, criando discípulos em condições de virem a poder dispensar o seu auxílio e de, por sua vez, instituírem novas unidades fabris.

0 processo de incremento industrial começou com a recuperação de uma fábrica já existente em Lisboa, próspera em anos anteriores mas agora decadente, fundada em 1734, durante a regência de $\mathrm{D}$. João $\mathrm{V}$. Trata-se da conhecida fábrica das sedas do Rato, cuja direç̧ão fora confiada a um francês, de nome Roberto Godin, instalada na zona de Lisboa chamada Cotovia, próxima do actual Largo do Rato, então arrabalde da cidade. Pombal encontrou-a em decadência mas com instalações utilizáveis e susceptível de ressurgimento. Não deixa de ser significativo que num país de tão baixo nível industrial tivesse havido interesse no estabelecimento de uma fábrica de sedas, contratando-se então operários de Lyon que vieram trabalhar sob a direcção do referido Godin. Agora Pombal ia aproveitá-la com especial interesse no fabrico de galões de ouro e de prata, que se importavam de França, e que tinham muito consumo particularmente "na tropa e no culto divino", usando as palavras de Ratton nas suas Recordações. Pensou também o secretário de Estado que para maior proveito económico conviria que o próprio fio de seda fosse produzido entre nós para o que seria necessário fomentar a cultura das amoreiras cujas folhas servem de alimento aos bichos da seda. Destinou-se para o efeito uma zona de terras de semeadura, próxima da Cotovia, exactamente aquela que na topo-

(') Jácome Ratton, Recordações, 2." ed., 1920, p. 28. 
nímia da cidade permaneceu com a denominação de Bairro das Amoreiras, além de que, na continuação do processo, também a plantação das árvores foi efectuada em diversos locais do país. Os pés das amoreiras vinham de França, mas chegavam muitas vezes ao seu destino inutilizados, impróprios para á plantação, em consequência da viagem demorada a que eram sujeitos, acomodados em más condições nos porões dos navios de transporte, onde suportavam temperaturas excessivamente elevadas para a sua conservação. $O$ já referido francês Jácome Ratton interveio no processo mandando vir, por sua iniciativa, não os pés mas as sementes das amoreiras que experimentou num viveiro de uma sua propriedade na Barroca de Alva, no concelho de Alcochete. $O$ resultado foi excelente; o próprio Pombal lhe comprou 2.000 pés das amoreiras semeadas, para a sua quinta de Oeiras, em substituição de outros tantos que mandara plantar e não tinham pegado. Economicamente os pés de amoreiras obtidos pela iniciativa de Ratton eram do maior interesse pois saíam a 300 reis cada um, enquanto os pés importados de França saíam quase pelo triplo, a 800 reis, conforme o próprio nos conta no seu já citado livro.

A área das Amoreiras, em Lisboa, foi aproveitada não só para a plantação das árvores mas também para a construção de grande número de edificações, umas fabris e outras para habitação dos mestres que trabalhavam nas diversas instalações. A Real Fábrica das Sedas, conforme era designada, permaneceu na Cotovia. As fábricas agora construídas nas Amoreiras não se destinavam à produção de quaisquer géneros em que figurasse a seda mas a muito diversas produções, como a seguir diremos; estavam porém todas sujeitas à administração da fábrica das sedas, considerada como fábrica-mãe.

As primeiras disposições de Pombal respeitantes ao progresso industrial do país têm todas em mira o melhoramento da produção de sedas, com a preocupação de assinar rapidamente contratos com desenhadores e tintureiros para laborarem na Real Fábrica, assim como a procura de tapeceiros que fossem habilitados na feitura dos afamados Gobelins. Parece que o secretário de Estado, que tomou posse do seu cargo em 1750, só se preocupou, até 1755 , ano fatídico do terramoto de Lisboa, com as citadas produções, no seu plano de reforma industrial. Todas as outras indústrias só começam a ter presença notória na década de 60 .

Possuímos, nos arquivos portugueses, muita documentacão relativa a estes temas, correspondência trocada entre componentes do Governo, incluindo o próprio ministro de D. José, e os nossos representantes diplomáticos em Paris, em Londres e na Haia. Umas vezes eram os diplomatas encarregados de 
procurarem, nos países em que se encontravam, os operários que nos convinham; outras vezes aproveitavam-se de operários que, tendo notícia dos nossos interesses, se iam apresentar espontaneamente nas legações portuguesas a oferecerem os seus préstimos. As negociaçōes eram sempre demoradas, pela lentidão da correspondência em ir e vir, e terminavam, quando eram bem sucedidas, pela vinda dos operários, com salários fixados bastante superiores aos que auferiam nos seus locais de trabalho de origem. Só assim um operário se disporia a abdicar da segurança do seu emprego, pois tratava-se de especialistas, para se transportar, em geral com mulher e filhos, para um país desconhecido.

Em 1751 (cronologicamente o primeiro caso relacionado com o assunto em causa) chega a Lisboa o francês Pierre Dangé, tintureiro, que andara pelas Indias em busca do segredo de certa tintura carmesim, que afirmava ter descoberto. Propõe-se, se o seu trabalho agradar, mandar vir um grupo de operários de França e instalar entre nós uma fábrica de fiacão $\epsilon$ tecelagem de algodão $\left(^{8}\right)$. Em 1752 Diogo de Mendonça Corte-Real escreve, de Lisboa, a Galvão de Lacerda, em Paris: "SMg.de he servido que vs." busque em Leaõ hum bom desenhador e hum bom Tintureiro p.a a Fabrica de Lisboa, e que achando-os capazes os ajuste». E termina: "SMg.de manda recomendar a vs. m. $t^{\circ}$ esta deligencia». Oito meses decorridos, e referindo-se ao tintureiro que ainda não se conseguira contratar, oficiava-se de Lisboa: «estamos esperando com bastante impaciência, porque a Fábrica não tem nenhum». Só em Outubro de 53 o tintureiro procurado chegou a Lisboa e desejou que se construísse uma Casa da Tinturaria, segundo desenho seu, após o que mostraria as suas capacidades. 0 desejo foi imediatamente satisfeito. $\mathbf{O}$ mestre tintureiro chamava-se Louis La Chapelle e, devido às excelentes informações que se obtiveram a seu respeito, fez-se-lhe o contrato por dezasseis anos, o que cumpriu com pleno agrado, acabando por ser um dos directores da Real Fábrica das Sedas. Morreu em Lisboa em $1770\left({ }^{9}\right)$.

$\left.{ }^{8}\right)$ Torre do Tombo, Minist. dos Neg. Estrang., Legação de Portugal em Inglaterra, Caixa B, ofícios de 5-I, 8-VI, 22-VI e 29-VI-1751.

( $\left.{ }^{\circ}\right)$ Idem, idem, Legação de Portugal em França, Caixa 4, ofícios de 18-I, 19-II e 19-IV-1753; e Despachos para a Legação de França, Caixa de 1736 a 1803, ofícios de 3-X-1752, 12-VI e 19-XI-1753. Veja-se também Matos Sequeira em Depois do Terramoto, Lisboa, 1917-1930, vol. III, p. 122. 
Quanto ao desenhador requisitado juntamente com o tintureiro, sabemos que também foi ajustado, mas mais tarde, c se chamava Thomas $\left({ }^{10}\right)$.

No ano seguinte, em 1754, ambos os nossos representantes diplomáticos, de Londres e de Paris, se ocupavam de conseguir tapeceiros. De Londres escrevia D. Luís da Cunha ao próprio Sebastião José de Carvalho e Melo informando-o de que lhe enviava, juntamente com a carta, «duas pequenas pessas $p^{2}{ }^{2}$ amostra das tapesarias $q$ aqui se fazem na fabrica de Fulham". O director da fábrica, Parizot, «intenta estabelecer nesse Reino huma semelhante fabrica». Por seu lado Galvão de Lacerda, em Paris, que andava, com impaciência, em busca de tintureiros, informava que fora procurado por Pedro Pepin. tapeceiro dos Gobelins, que pretendia ser contratado para Portugal. A aquisição seria valiosa. Segundo declara, na Memória que apresentou ao nosso representante, fora esse tapeceiro "qui a eû l'honneur de travailler à plusieurs pieces de Tapiserie qui sont actuellement chez Sa Majesté Porturaise». Pepin declarava já ter obtido a sua dispensa da manufactura dos Gobelins e que podia passar a Portugal "sans danger» ${ }^{11}$ ).

Além das buscas insistentes de desenhadores, tintureiros $\epsilon$ tapeceiros, como se fossem produtores de géneros de nrimeira necessidade, só temos notícia, no período de 1750 a 1755 . de buscas relativas à contratacão de um mestre de pólvora. Em Fevereiro de 55 Melo e Castro oficiava da Haia dizendo que "Sua Mag..$^{e}$ foi servido ordenar-me q buscar-se hũ Mestre p." a Fabrica da Polvora». Arranjou-se o homem desejado, e católico romano. Chamavarse Gerret Albers, e era mestre de uma das fábricas de pólvora de Amesterdão. Fez-se o ajuste por seis anos com a habitual condição de "ensinar todos os off.es Portuguezes, sem pôr difficuldade alguma a descobrirlhes e mostrarlhes a forma com q se trabalha nas Fábricas das outras Potencias». Quatro meses depois de estar em Lisboa, o mestre Albers queixava-se «de q dous Officiaes Portuguezes antigos na Fabrica, . $^{2}$ lhe tirarem o credito, lhe faziaõ misturas de alguns ingredientes, de sorte $\mathrm{q}$ as fornadas se perdiaõ, e que querendo queixarse, o intimavaõ com ameaças; à vista do que dezejava voltar p. $^{2}$ Amsterdam». Fora mal rece-

$\left({ }^{10}\right)$ Ofício de $19-\mathrm{XI}-1753$ referido na nota anterior.

(") Torre do Tombo, Minist. dos Neg. Estrang., Legação de Portugal em Inglaterra, Caixa B, ofício de 8-XI-1754, e Papéis de Diogo de Mendonça Corte-Real que vieram do Conselho de Guerra, Maço 251, ofício de 16-IX-1754. 
bido, ou então não teria o préstimo de que se arrogava e preferia retirar-se $\left({ }^{12}\right)$.

0 terramoto de 1 de Novembro de 1755 veio desarticular toda a vida de Lisboa e, por reflexo, a da nação, e desviar as atenções dos governantes para a busca de remédios urgentes que sarassem, no mais breve prazo, as profundas e gravíssimas feridas abertas no corpo social português já tão necessitado de medicação. Necessariamente tudo quanto se projectava realizar ficou atrasado na sua realização e foi preciso que os anos se sucedessem, que a calma regressasse aos espíritos, que as pessoas perdessem o medo e se dispusessem a acreditar que valia a pena regressar de novo às suas normais actividades.

$\mathrm{Na}$ década de 60 reata-se, com entusiasmo, o projecto de instalação de fábricas e de oficinas, agora com fins diversificados que anteriormente não tiveram, não só em Lisboa como na província. Começam a erguer-se, no Bairro das Amoreiras, as instalações fabris e as habitações para os profissionais nelas ocupados, multiplicam-se as buscas no estrangeiro e os contratos com mestres e operários, e o sistema entra em progresso crescente com êxito acentuado na década seguinte, embora algumas das unidades industriais estabelecidas de raiz não tenham conseguido prosperar. A Real Fábrica das Sedas continuou a ser o núcleo aglutinador de grande número de instalações fabris, sujeita à superintendência da Junta do Comércio.

Enunciaremos a lista de estrangeiros que foram procurados pelos serviços do Estado, ou por estes aceites por oferecimento dos próprios interessados, que dirigiram fábricas e oficinas, ou nelas trabalharam auxiliando-nos na construção de um progresso para que não nos mostrávamos preparados, mesmo nos casos de indústrias de fáceis instalações e prática de poucas exigências $\left({ }^{13}\right)$ :

Fábricas de chapéus criadas em Pombal e em Elvas por iniciativa de Jácome Ratton, em que trabalharam os franceses Sauvage, Guillaume Fournol. Albert Jacquerie de Salles, Jean Baptiste Alexis e Gabriel Milliet; fábrica de meias, cujo mestre foi o francês Noel Le Maitre, anexa à Real Fábrica das Sedas; fábrica de botões, com Bartolomeu Orsini, onde trabalha-

(12) Idem, idem, Legação de Portugal nos Paises Baixos, Caixa 2 , ofícios de 2-I, 6-II, 28-IV e 18-IX-1755.

${ }^{(13)}$ Resenha colhida através das obras de José Acúrcio das Neves, Jácome Batton e Matos Sequeira, já citados, de Jorge Borges de Macedo, em Problemas de História da Indústria Portuguesa no século XVIII, Lisboa, 1963, e José Barbosa, Para o estudo das origens da Indústria em Portugal, em Vértice, vol. 22, Coimbra, 1962. 
ram seu filho, Manuel, e os operários Francisco Fusquilli, Pedro Andrino, Francisco Oberti e Jacquerie de Salles, já referido; fábrica de galões de ouro e prata, anexa à Real Fábrica, cujo mestre foi Estevão José de Aza, a quem sucedeu José Pontremo; fábricas de fiação, uma em Tomar, fundada por Noel Le Maitre, já citado, coadjuvado por Edmundo Carlos Binet, Timoteo Lecussan Verdier, Jácome Ratton e Félix Clamouse Paliart, e outra em Lisboa, cujo mestre foi Ricardo Tinzelay, ao qual se seguiu Francisco Agostinho Guilhobel; fábrica de tecelagem, em Torres Novas, de David Sudhe e Henrique Menson; fábrica de fazendas brancas, em Sacavém, de Guilherme Macormik; fábrica de algodões, de João Baptista Locatelli; fábrica de cambraias e esguiões, em Almeirim, depois transferida para Alcobaça, com o mestre italiano Tacinari; oficina de tapeçaria, em Tavira, com Pedro Leonardo Mergoux; fábrica de cutelaria, com Jacques Dutoit, mais tarde substitu'do por António João Baptista Charlier, onde trabalharam Honoré Lambert e Hubert Joseph; fábrica de serralharia, criada por determinação da Real Fábrica das Sedas com a finalidade de construir e reparar teares, de que foi encarregado o genovês Pedro Schiappa Pietra, onde trabalharam João Baptista Bocalandro e Del Cuôco, passando posteriormente o contrato para seu irmão João Baptista Schiappa Pietra; fábricas de limas, uma em Pernes, fundada por Pedro Schiappa Pietra, e outra em Alcântara, com o irlandês Mateus Walker; oficina de fundição de metais, cujo mestre era o mantuano Júlio Gatti e contramestre seu filho André; fábrica de pentes de marfim, de caixas de papelão e de vernis, com o francês Gabriel de La Croix, em que trabalharam João Latau, João Pomier, Filipe Lamite e António Rustier, e que teve filial em Tomar, dirigida por Jorge Reynier; fábrica de charões, com o alemão José Ridler; oficina de candeeiros de estanho, com o italiano Jácome António Gulianetti; oficina de charneiras metálicas, com Luís Joaquim Sicard: oficina de folhetas para cravação de pedras, com Augusto Ludovice Thime; fábrica de chumbo de munições, com Jorge Reynier; oficina de colocação de aço nos espelhos, cujo mestre tinha o apelido Ghira; oficina de ligas de fio de ouro e de prata, e de lantejoulas de cores, com o francês Razuret; fábrica de estamparia, em Azeitão, de Estevão Garché; fábrica de quinquilharia, em Alcobaça, de Fernando José Loran; fábrica de artigos de cabedal, "pelica, de peles de anta e de camurça, e bem assim dos artefactos em que entram estas matérias primas, como luvas, véstias e calções» do irlandês Patrício Ryan; oficina para fabrico de letras de imprensa, de Henrique José Belinque; fábricas de azeite de peixe extraído da sardinha, uma em Aveiro, de João Baptista 
Locatelli, e outra em Ovar, do francês Minjoal; fábrica de relógios, de Cláudio Berthoud, mais tarde substituído por António Durand, onde trabalharam Henrique Ludovico, Nicolau Ugote, Joaquim Francisco Bigot, Francisco Guilhobert, Pedro Rozani c João Jácome Brunieri; fábricas de loiça, uma situada no Rato, cujo mestre foi Tomás Brunetto, italiano, e outra em Queluz, de Robillion; fábrica de faianças com o italiano Paulo Paulette; e fábrica de vidros, na Marinha Grande, do inglês Guilherme Stephens.

A apresentação da longa resenha, onde excluímos diversos casos insuficientemente definidos, corre o risco de ser enfadonha, mas pareceu-nos indispensável para tornar bem sensível a participação dos estrangeiros no plano de animação industrial do nosso país. Acrescentaremos ainda que foram contratados, em 1764, pela Real Fábrica das Sedas, o francês João Maria Policarpo May, do centro sericícola de Lião, para reger uma Aula de Debuxo, e o italiano João Grossi para exercer o ensino na Aula de Estuque e Desenho.

O terramoto de 1755 deixou a cidade de Lisboa reduzida, em grande parte, a um amontoado de escombros calcinados em quem ninguém ousou tocar nos primeiros dois anos e meio seguintes com receio de que novos abalos provocassem novas derrocadas $\left({ }^{14}\right)$. No estrangeiro a notícia da catástrofe despertou o interesse de vários profissionais que pretenderam ser contratados para as obras de reedificação da cidade. Na correspondência de Galvão da Lacerda, nosso representante diplomático em Paris, encontram-se alguns ofícios dirigidos à corte em que se refere a ofertas de arquitectos, ofertas que não sabemos que futuro tiveram. Existiam então dois arquitectos portugueses que já tinham dado provas de grande capacidade profissional e que o ministro de D. José se dispôs a aproveitar. Foram eles Eugénio dos Santos, arquitecto das obras dos paços reais, que traçou a planta da nova cidade, e Manuel da Maia, engenheiro-mór do Reino. A par destes, porém, foram em maior número os estrangeiros convidados para o efeito. Um deles, o húngaro Carlos Mardel, já vivia em Lisboa, e fora

(14) «Como o lapso de tempo que tem corrido desde o infausto dia do Terramoto até o prezente tenha desvanecido o receyo que podia haver de se bolir nos entulhos das ruinas desta Cidade, achou S. Mag.• ser ja tempo de se principiar a sua reidificaçaõ.» (Torre do Tombo, Papéis de Diogo de Mendonça Corte-Real, Maço 297, ofício de 2-VI-1758). 
arquitecto do aqueduto das Águas Livres. Agora, entre várias obras, procedeu à construção do Convento de S. Domingos, do Colégio dos Nobres, do palácio de Carvalho e Melo, em Oeiras, do chafariz da Rua Formosa, fronteiro à casa de habitação do secretário de Estado, etc. Outro arquitecto estrangeiro, com marcada actividade nesta época, foi o inglês Guilherme Elsden, a quem anos depois o já então marquês de Pombal nomeou Director das Obras da Universidade de Coim. bra. Foi Elsden que planeou todos os novos edifícios construídos nessa cidade, incluídos no programa da reforma dos estudos superiores. Foi também Elsden o encarregado dos melhoramentos da barra de Aveiro.

De outros arquitectos e engenheiros estrangeiros temos notícia nesta época, não só para a reedificação da cidade como para outras obras no país. João Antinori, arquitecto, ajudante de Eugénio dos Santos, fez o risco do palácio real projectado para se erguer em Campolide; Giacomo Azzolini, encarregado de reedificar o Convento de S. Bernardo, em Lisboa, e o Seminário de Coimbra; João Carlos Bibiena, arquitecto supranumerário das obras dos paços e quintas reais, que fez o risco da Igreja da Memória, em Lisboa e, logo após o terramoto. o traçado da capela real e do paço da Ajuda para albergar provisoriamente a família real; Nicolau Nazoni, célebre arquitecto italiano que fixou residência no Porto e aí construiu os edifícios dos Clérigos e da Misericórdia; o arquitecto bolo nhês João Francisco Famossi, que dirigiu, com Azzolini, as obras do Seminário de Coimbra; os engenheiros Heldes e Polchete que, juntamente com Elsden, procederam ao estudo dos melhoramentos da barra de Aveiro ${ }^{15}$ ).

Em matéria de obras públicas e no que respeita à construção de estradas mantivemo-nos, no tempo de Pombal, na mesma situação desastrosa em que nos encontrávamos antes da sua acção governativa, isto é, sem estradas. Em 1768, o nosso representante na Haia, Vasques da Cunha, em ofício para Lisboa, apresentava um francês, o capitão Chardon que, pelas informações colhidas, tinha grande "prática da construcção dos caminhos publicos à moda d'Alemanha, a que chamaõ em Frances Chaussée, ou ferré». Aconselhava o diplomata que se contratasse aquele francês "pois até agora não temọ no Reino

$\left({ }^{15}\right)$ As informações deste teor podem colher-se em Sousa Viterbo, Dicionário Histórico e Documental dos Architectos, Engenheiros $e$ Constructores portugueses ou a serviço de Portugal, Lisboa, 1899-1922 . 
estradas feitas, q. $\mathrm{d}^{\circ}$ no resto da Europa ainda as pequenas Potencias as tem posto neste Seculo em grande prefeição" $\left({ }^{16}\right)$.

A reconstrução da cidade, após o terramoto, exigiu o consumo avultado de diversos materiais, como sejam pedras, tijolos e cal. Não seria necessário importá-los nem certamente contratar pessoal estrangeiro para os utilizar na construção dos edifícios. Contudo, não deixou de figurar nesse processo um hábil estrangeiro que, por aquiescência dos governantes, teria tirado bom proveito da nossa infelicidade. Trata-se do inglês William Stephens, à data do terramoto já residente em Lisboa, o mesmo Stephens que em 1769 criou a conhecida fábrica de vidros da Marinha Grande tornando-a, com seu espírito dinâmico, uma das instalações fabris mais importantes da Europa. Stephens requereu ao rei D. José o direito exclusivo de fornecer a cal necessária à reedificação de Lisboa, e o rei acedeu. Já então o industrial inglês possuía fornos de cal em Alcântara para calcinação da pedra calcária de onde recolheria a cal. O calcário tinha de ser aquecido nos fornos e o combustível usado no aquecimento era a lenha nacional. Stephens entrou em contacto com o embaixador inglês em Lisboa, Eduardo Hay, e com ele planeou uma acção conjunta no sentido de utilizarem, no aquecimento do calcário, não a nossa lenha, mas um carvão inglês, que seria importado, um carvão designado culm, pulverulento, de muito fraca qualidade, e que, por isso, não tinha praticamente saída na Inglaterra. $\mathbf{O}$ ministro inglês escreveu de Lisboa à Tesouraria de Londres para se conseguir que o culm saísse de Inglaterra pagando direitos diminutos, enquanto um certo Dingley, correspondente de Stephens na capital inglesa, procurava o nosso representante nessa cidade, Melo e Castro, para que este se avistasse com os ministros de Estado ingleses a fim de obter o apoio favorável aos interesses de Stephens. Segundo o critério dos ingleses tudo isto seria de grande vantagem para nós, portugueses, conforme o embaixador Hay escreve na sua petição à Tesouraria de Londres, referindo-se ao "contracto com a corte de Portugal, p. ${ }^{a}$ fornesser a Cal necess. ${ }^{2}$ p. $^{a}$ a reedificação desta Capital, e servir-se do Culm de Inglaterra»: "Este Contracto, se se lhe der proteç̧ão, será utilíssimo p. ${ }^{2}$ as duas Nações, porq contribuhirá p. a extracção do nosso Culm, a qual não tinha antecedentem.te $\mathrm{t}^{\mathrm{e}}$ e augmentará consideravelm. $\mathrm{t}^{\mathrm{e}}$ a nossa Navegaçaõ, pelo n..$^{\circ}$ de Navios q seraõ empregados no transpor-

${ }^{\left({ }^{16}\right)}$ Torre do Tombo, Minist. dos Neg. Estrang., Legação de Portugal nos Países Baixos, Caixa 5, ofício de 22-III-1768. Não temos notícia do proveito que teria tido esta diligência. 
te: A utilid. $\mathrm{q}$ rezulta a Portugal, he de rezervar a sua lenha, de $q$ tem necessidade p. outros uzos» $\left.{ }^{17}\right)$. O desejo de Stephens foi satisfeito, e assinado o contrato para a exportação de culm com validez de quinze anos.

Sete anos após o terramoto de Lisboa, com a cidade ainda em grande parte em ruínas, nova calamidade nos assola: a guerra. Desencadeara-se, em 1756, um conflito entre a Inglaterra e a França, que viria a prolongar-se até 1763: a chamada Guerra dos Sete Anos. No decurso dos acontecimentos a Espanha aliou-se à França, assinando o Tratado conhecido por Pacto de Família (os Bourbons), e ambas planearam a invasão de Portugal para nos obrigarem a fechar os nossos portos à Inglaterra. Como tal atitude, da nossa parte, contrariava os compromissos da secular aliança luso-britânica, negámo-nos à inclusão de Portugal no Pacto de Família, que se pretendia, o que, por reflexo, nos colocou no teatro da guerra.

Mal tinham surgido os primeiros rumores dos perigos a que iríamos estar sujeitos, viu-se Pombal obrigado a preparar a defesa da nação e a encarar a situação das nossas forças armadas. Há doze anos que ocupava as cadeiras do Poder e ainda não tinha lançado um olhar sobre o nosso exército e a nossa armada cujo estado era deplorável. Não há vozes discordantes neste pormenor, «embora doa ao nosso patriotismo confessá-lon, conforme escreveu um dos estudiosos desta época da nossa história ${ }^{18}$ ). O nosso exército, com insuficiente número de efectivos, era comandado aos mais altos níveis por nobres, cuia nobreza, só por si, justificava essa função embora não tivessem preparação para ela. Os oficiais subalternos eram os próprios servidores das casas desses nobres. Os soldados, recrutados entre camponeses. não tinham uniformes nem armamento, e angariavam esmolas para poderem sobreviver. $\mathrm{Na}$ verdade, como não haviam de morrer de fome os pobres soldados portugueses se, durante longos meses, como aliás também sucedia com os próprios oficiais, não se lhes pagava salário? Em Novembro de 1761 já se contava ano e meio que ninzuém, no exército, recebia o que lhes era devido $\left({ }^{10}\right)$. Em melhores condiçōes se encontravam os marinheiros que ao desembarcarem nos portos estrangeiros fugiam e

${ }^{(17)}$ Idem, idem, Legação de Portugal em Inglaterra: Caixa 1, a carta citada, em inglês, assinada Edw.d Hay, de 11-XI-1757; Caixa 2, tradução portuguesa da carta anterior, anexa ao ofício de Melo e Castro, de 15-II-1758, e ofícios de 31-I, 15-II e 30-V-1758. 1937 , p. 49.

(18) Pereira Sales, O Conde de Lippe em Portugal, Famalicão,

(10) Lúcio de Azevedo, ob. cit. 
iam procurar ganhar a sua vida de outro modo ou ingressavam na tripulação dos navios desses países. Disso se queixam os nossos diplomatas como D. Luís da Cunha que escrevia de Londres dizendo que eram "inumeráveis» os marinheiros portugueses que serviam os ingleses e «infinitos» os que serviam os franceses $\left({ }^{20}\right)$. Agora que estávamos em guerra andava-se à caça dos marinheiros em Londres para os obrigar a regressar à pátria: "Allem dámanhã partirá daqui hum Hyate de Setubal carregado de Marinheiros Portuguezes. Pelo Capitaõ do d..$^{\circ}$ Hyate escreverei ao Ex. ${ }^{\text {mo }}$ Snr. Fran..$^{\circ}$ Xavier de Mendonça, para que Elle mande tomar conta da dita carga, que espero seja de bastante utilidade ao Serviço d'ElRey N.S." ( ${ }^{21}$ ).

Que fazer então para acudir, com urgência, à situação desesperada do nosso exército, com o inimigo à porta, prestes a atravessar as nossas fronteiras, como realmente veio a suceder? A solução apresentava-se só uma, a de pedir auxílio ao estrangeiro, necessariamente à Inglaterra porque, independentemente dos compromissos da nossa aliança, estava aquele país interessado na utilização dos portos portugueses que poderia vir a perder no caso da invasão espanhola. Iniciou o conde de Oeiras, logo nos primeiros dias de 1762, as devidas negociações com a Grã-Bretanha, pedindo-lhe soldados, equipamentos e armamentos, a que os ingleses acederam sem quaisquer delongas, instigados pela urgência que a situação requeria e por reconhecerem que, da nossa parte, nos limitávamos a aguardar a sua ajuda sem nada fazermos por nós próprios. Conforme escrevia Melo e Castro, nosso representante em Londres: "A este Ministério" [o inglês] "tem feito grande impressaõ naõ ter not." alguma de preparos q se façaõ em Portugal, conhecendo o perigo evidente a $\mathrm{q}$ todo o $\mathrm{Rn} .^{\circ}$ se acha exposto». $\mathrm{E}$ acrescentava que a Inglaterra "entrará na mayor consternação, e abatimen.$^{\circ}$, se vir q os Hespanhoes penetraõ em Portugal sem alguma rezistencia, q nos chamaraõ indolentes, irrezolutos, e tudo o mais que vier ao pensam.t $t^{\circ}[\ldots]\left({ }^{22}\right)$.

Em Maio de 1762 começaram a chegar a Portugal as primeiras forças armadas inglesas, sete a oito mil homens, e um grupo de oficiais de altas patentes que viriam a comandar os nossos regimentos (Cary, Crawford, Lenox, Townsend, Macleane, Smith, e outros). Constituiram estes militares o primeiro

${ }^{\left({ }^{\infty}\right)}$ Torre do Tombo, Minist. dos Neg. Estrang., Legação de Portugal na Inglaterra, Caixa C. ofício de 23-XI-1756. Foi publicado sobre o assunto um alvará em 27-IX-1756. 15-III-1763.

(") Idem, idem, idem, Caixa 6, ofício de José de Sá Pereira, de

${ }^{(2)}$ Idem, idem, idem, Caixa 5, ofício de 2-II-1762. 
grupo de mais nomeada porque, após eles, sucederam-se as vindas de oficiais de patente em número elevadíssimo que exigiriam dezenas de linhas para sua enumeração completa. Eram de várias nacionalidades, uns nomeados pelo rei inglês expressamente para o serviço de Portugal, outros escolhidos entre os que se dirigiam aos nossos representantes diplomáticos oferecendo os seus préstimos, normalmente aceites. $E$ bem característico do século XVIII a existência de verdadeiros profissionais da guerra, militares de patente que acorriam aos locais onde os exércitos se defrontavam, oferecendo os seus serviços na mira de recolherem benesses em pagamento da sua actividade guerreira, benesses que lhes permitiriam amealhar para os tempos de paz e garantirem-lhes certo desafogo económico quando chegassem à velhice. "Vou tomando os Off.es de prestimo q se me prezentaõ, na forma q V. Ex. ${ }^{2}$ terá visto, e são tantos que me não falta onde escolher", escrevia Melo e Castro. Alguns dos militares que vieram até nós eram de elevada estirpe, de títulos nobres, e entre eles, como expoente máximo, o príncipe Carlos Luís Frederico, duque de Mecklembourg, irmão da rainha de Inglaterra. Chegou em Julho, e foi nomeado "Lugar-tenente General dos meus Exércitos».

Assim se encheu o país de muitas dezenas de oficiais estrangeiros, uns superiores, outros subalternos, ingleses, irlandeses, suiços, alemães, suecos, dinamarqueses, além de outros já entre nós instalados anteriormente à situação de guerra que então se vivia, oficiais que os nossos governantes acolhiam com agrado, dando-lhes boas condições de vida e destinandoos a serviços que, por vezes, deveriam competir a personalidades portuguesas. E o caso, por exemplo, do general francês Guilherme de Valleré que, em 1758, em tempo de paz, sem necessidade de auxiliares estrangeiros, era quem fazia a guarda do paço da Ajuda com um regimento a isso destinado, o mesmo oficial que, no ano seguinte, foi mandado participar na prisão dos jesuítas na Universidade de Evora. A par de Valleré poderíamos citar muitos outros, instalados em Portugal em anos anteriores aos da guerra com a Espanha, mas já com D. José, como o brigadeiro Cláudio Paradiz, o capitão de mar e guerra das naus, Rolin Wandre, o capitão de infantaria Tossi Colombina, o coronel de artilharia João Alexandre de Chermont, o catalão Romaguerra Colomer, governador do Forte de Santo António de Tavira, etc., etc. $\left({ }^{28}\right)$.

${ }^{(2)}$ A presença destes militares de patente, e de muitíssimos outros, em Portugal, pode confirmar-se em Cláudio Chaby, Sinopse dos decretos remetidos ao extinto Conselho de Guerra, Lisboa, 1869. e em Madureira dos Santos, Catálogo dos decretos do extinto Conselho de Guerra. 
Faltava agora escolher quem deveria tomar o encargo de dirigir superiormente os exércitos, português e estrangeiro, no nosso território. Naturalmente que o êxito da defesa da nação dependeria essencialmente da personalidade que ocupasse o lugar de comandante supremo, o qual deveria ser homem treinado nas acções de guerra, duro, inflexível, temido, respeitado, disciplinador. $\mathrm{Na}$ dúvida, decidiu $\mathrm{D}$. José consultar o rei da Grã-Bretanha que lhe sugeriu, como pessoa competente, o príncipe de Bevern, então em serviço do rei da Prússia. Embora de princípio as negociações com Bevern corressem favoravelmente, não chegaram ao termo desejado, o que tornou necessário considerar uma segunda hipótese. Desta vez a sugestão do rei de Inglaterra foi no sentido de se convidar o conde de La Lippe Schaumbourg, inglês de nascimento, de momento ocupado no comando de tropas em Hanover. D. José enviou-lhe uma carta de convite que, por curiosa coincidência teve exactamente a mesma data (30-IV-1762) em que os espanhóis, concentrados desde Março nas nossas fronteiras, entraram por Trás-os-Montes e iniciaram as hostilidades.

Lippe respondeu poucos dias depois do convite, de $\mathrm{Bu}-$ ckebourg onde então se encontrava, e admitia a hipótese de o aceitar, prevenindo-se porém desde já contra o possível desaire da sua intervenção na defesa de Portugal, e exigindo autorização para o livre exercício da sua religião de protestante para o que seria acompanhado do seu capelão particular. Foi-lhe respondido que sim, acrescentando-se que poderia trazer consigo quatro das Companhias que tinha na Alemanha sob seu comando, a cujos soldados seriam atribuídos os mesmos salários que aí recebiam, ou mais, se Lippe achasse pouco, assim como também poderia vir acompanhado dos oficiais que entendesse, os quais receberiam, em Portugal, o dobro do soldo recebido pelos oficiais portugueses de igual patente.

Feito o contrato Lippe dirigiu-se para Portugal e chegou a Lisboa em 3 de Julho de 1762. Por decreto dessa mesma data, o Conde Reinante Guilherme de Schaumbourg Lippe, Conde Soberano de Schaumbourg, Conde e Nobre Senhor de La Lippe e de Sternberg, Cavaleiro da Ordem Real e Prussiana da Águia Negra, conforme é denominado no documento, foi nomeado Marechal General do Exército do Reino. Logo no dia seguinte $\mathrm{D}$. José recebeu-o em audiência particular e foi informado de que teria habitação condigna e que "sa Table est servie par les Officiers de la Cour» $\left({ }^{24}\right)$.

(') Torre do Tombo, Legação de Portugal em Inglaterra, Caira 5 , carta do conde de Oeiras, de 10-VII-17.62. 
Lippe não desembarcou sozinho em Lisboa. Seguia-o vasta comitiva de militares de sua confiança, quase todos alemães: o coronel Böhm, governador de Bremen, e o coronel Hamilton, 2 majores, 6 capitães, 4 tenentes, 5 oficiais inferiores, 2 sargentos, 33 praças, mineiros, artífices, bombardeiros e artilheiros num total de 15, 1 porta-estandarte, e também 1 engenheiro geógrafo, o médico privado, o seu «maitre d'hôtel», criados de quarto, cozinheiros e escudeiros. Em breves dias após a sua chegada estabeleceu quartel-general em Abrantes e rapidamente traçou o plano de defesa contra a investida dos espanhóis que já se encontravam de posse de uma parcela do nosso território e, seguidamente, o plano da sua expulsão.

Foi brilhante a acção de Lippe, mas pouco fácil. Uma das causas das dificuldades que encontrou foi a resistência passiva e a guerra de intrigas que lhe foi declarada pelos oficiais portugueses de alta patente, submetidos às ordens dos militar res estrangeiros que tinham tomado o comando dos regimentos e o governo das praças fortes, e sem dúvida também revoltados pelo inferior soldo que recebiam relativamente a esses estrangeiros. Por seu lado, esses oficiais estrangeiros, incluindo Lippe, sentiam-se surpreendidos com o desinteresse e a passividade dos nossos sem saberem como remediar a estranha situação. Melo e Castro, de Londres, escrevia: «Eu naõ sei quáes saõ os Fidalgos de quem aqui se fála com tanto oprobrio, nem posso crer o q delles contaõ; sei porem, q o Ministerio q. $\mathrm{d}^{\circ}$ lhe pesso soccorros, e mayor assistencia me responde, fazendo-me o discurço q deixo ponderado, e concluindo, $q$ saõ innuteis mayores assistencias, emq. $t^{\circ}$ os Portuguezes naõ mostraõ q se querem defender com as q já lhe foraõ» $\left({ }^{28}\right)$.

A guerra entre Portugal e a Espanha durou somente alguns meses. Os acontecimentos corriam desfavoravelmente para os colaborantes do Pacto de Família. A Espanha pediu-nos um armistício em Novembro desse mesmo ano de 1762, t a paz definitiva entre ela e a França por um lado, e a Inglaterra por outro, foi assinada em Fevereiro do ano seguinte.

D. José, reconhecido pelas vitórias que o conde de Lippe lhe proporcionara, decretou que em todos os seus reinos $\mathrm{e}$ domínios, sem excepção de lugar ou pessoa, se lhe desse o tratamento de "Alteza", tanto por palavra como por escrito, e solicitou-lhe que permanecesse por mais algum tempo no nos-

(25) Idem, idem, Caixa 5, ofício de 21-X-1762. Repare-se em que $o$ ofício é do mês de Outubro e que Lippe veio para Portugal em Julho. 
so país para reorganizar o exército e melhorar as fortificações. Lippe aceitou e manteve-se em Portugal até Setembro de 1764, o que corresponde a uma estada de um total de quase três anos, dos quais cerca de dois já em clima de paz. Ia agora sair do país mais pela necessidade de descansar e de olhar pelos seus bens pessoais que deixara na Alemanha do que por decisão de abandonar o cargo que exercera. Era possível até que regressasse, como de facto veio a acontecer. Em despedida D. José presenteou-o com o seu retrato cercado de diamantes, um emblema, também de diamantes, da Ordem da Águia Negra a que Lippe pertencia, um par de fivelas de diamantes para os sapatos e para os calções, seis miniaturas de peças de artilharia feitas de ouro maciço cada uma das quais de seis quilogramas e meio, assentes em carretas de ébano, $\epsilon$ que lançavam balas. Além dos citados presentes resolveu também D. José manter-lhe o título de Comandante em Chefe do Exército Português e de lhe pagar os vencimentos de marechal-general por toda a vida, o que orçava em três mil libras esterlinas anuais. Lippe, galhardamente, não quis aceitar está avultadíssima importância justificando a recusa por não ter vindo ao nosso país na qualidade de mercenário $\left({ }^{28}\right)$.

Com Lippe saíram também de Portugal os oficiais, quase todos alemães, que tinham constituído a sua comitiva, a cada um dos quais foi dada a gratificação de mil e duzentas libras. Ficou, porém, entre nós um deles, o capitão Colson, com o encargo de informar Lippe do que se fosse passando em Portugal, no respeitante a actividades militares, ao qual foi atribuída a designação de "Conselheiro da Corte».

Alguns meses antes da saída de Lippe já o conde de Oeiras tomava providências no sentido de procurar um militar que substituísse aquele quando se ausentasse. As negociações foram efectuadas em França com o barão de Closen, marechal de campo ao serviço do rei francês numa situação económica altamente qualificada. Pombal ordenou que lhe fizessem ofertas que ultrapassassem largamente todos os benefícios que

$\left({ }^{26}\right)$ Pereira Sales, ob. cit., pp. 142 a 152 , onde se indicam as fontes documentais respectivas e de cuja leitura se conclui que as 3 mil libras esterlinas equivaliam, em 1931, a cerca de 500 contos. As informações aí dadas acrescentamos as palavras de um ofício de Melo e Castro ao conde de Oeiras, datado de 12-XI-1765, em que se refere à visita que Lippe lhe fez, no regresso de Portugal: «O mesmo Marechal me disse «q. d $^{\circ}$ aqui se acháva, que El Rey Nosso $\mathbf{S}^{r}$. fizera com Elle huma despeza excessiva e desnecessaria; e que quando voltásse a Portugal,o que esperáva fazer no termo de dous Annos, hera indispensavelmente precizo, reduzir este Artigo, aos termos da moderação, que então não tivera». (Legação de Portugal em Inglaterra, Caixa 8). 
então recebia, soldos, pensões, casa, comendas, etc., e mais o hábito de Cristo. Closen aceitou mas exigiu, além disso tudo, que lhe fossem oferecidas terras de rendimento. Foi-lhe respondido que sim, que teria tudo quanto quisesse. Entretanto não veio, porque o rei de França declarou exercer represálias sobre ele se abandonasse aquele país $\left({ }^{27}\right)$. A questão resolveu-se com o regresso a Portugal do coronel Böhm, um dos componentes da comitiva de Lippe. Veio em condições excelentes, e apenas exigiu mais uma que alegou já ter sido concedida a outros: que a sua bagagem não fosse fiscalizada quando desembarcasse... $\left({ }^{28}\right)$.

Os oficiais estrangeiros saídos de Portugal depois de feita a paz com a Espanha foram somente os que Lippe trouxera consigo em 1762. Todos os outros, que eram largas dezenas, se mantiveram no país ocupando os seus postos de comando e alguns em posições cimeiras como a de governadores de praças fortificadas. Assim, em 1763, Pascoal Pepper era governador da praça de Marvão; Simão Fraser, governador das armas da província de Trás-os-Montes e da praça de Chaves; Guilherme Sharpe, governador da praça de Olivença; Francisco Maclean, governador da praça de Almeida; Paulo Damont, governador da praça de Arronches; Carlos Massê, governador da praça de Juromenha; e Carlos Chauncey, inspector geral das tropas na Corte. Nos anos sucessivos não cessaram os contratos assinados com novos oficiais que continuavam a acorrer às nossas embaixadas, tanto para servirem no exército como na marinha $\left({ }^{29}\right)$.

Lippe deixara Portugal em Setembro de 1764 mas ainda antes do fim desse ano já D. José lhe escrevia pedindo-lhe que regressasse. Lippe respondeu que a sua presença em Portugal

(2) Legação de Portugal em Inglaterra, Caixa 7, vários ofícios, e documentos anexos, dos meses de Março a Maio de 1764 .

$\left.{ }^{23}\right)$ Idem, idem, ofícios de 5-VIII, 18-XI e 4-XII-1764. Böhm manteve-se em Portugal e em 1767 foi nomeado comandante das forças armadas portuguesas no Brasil, para onde partiu.

$\left.{ }^{20}\right)$ Contámos, na Sinopse e no Catálogo dos decretos sobre assuntos militares a que nos referimos na nota 23, um total de 339 oficiais estrangeiros que estavam presentes em Portugal, exercendo funções, nos anos que decorrem entre o fim da guerra com a Espanha (1763) e a destituição do marquês de Pombal (1777). Todos esses oficiais figuram nos decretos pelo motivo de terem sido promovidos ou transferidos de funções, devendo-se notar que alguns desses nomes, poucos, se repetem porque, no intervalo de tempo considerado, tiveram mais de uma promoção ou transferência. Obviamente não figuram nos decretos os nomes dos oficiais estrangeiros que, estando presentes em Portugal, não foram promovidos nem transferidos durante aqueles anos. 
não tinha utilidade nenhuma desde que não se tivesse preparado seriamente o país no respeitante a armamento, a carros de transporte militares, a cavalos, a municiamento das fortalezas, a tendas de campanha, etc., etc., de acordo com as instruções que deixara ficar antes de regressar à Alemanha.

Corresponde exactamente a esse ano de 1764 a vinda, para Portugal, de dois fundidores e fabricantes de armas, franceses, de nomes Drouet e Brocard. Pela sua vinda se interessou Pombal directamente escrevendo sobre esse assunto, e insistindo nele, ao nosso ministro em Londres, Melo e Castro. «O Fundidor Drouet» - escreve Pombal — «se acha trabalhando em erigir novas Maquinas, e huâ amplíssima fornalha, donde podem sahir oito Peças de trinta e seis em cada fundição. Também chegou, e fica trabalhando com elle o outro Fundidor Pedro Brocard" $\left({ }^{30}\right)$.

Segundo conta Ratton nas suas Recordações (p. 232) foi este Drouet, por ordem do Governo, percorrer o país em busca de argila refractária "até entaõ desconhecida no Reino; pois que se usava dos tijolos ordinarios na construção dos fornos de fundição, com o inconveniente de ser preciso hum novo forno para cada fundição". Drouet descobriu a argila refractária nas proximidades de Aveiro e aí estabeleceu fornos e fábrica de tijolos refractários. Também segundo Ratton trabalhou Drouet no Arsenal Real do Exército, em Lisboa, em Santa Apolónia, e aí construiu um forno de revérbero e realizou vários inventos "como tornos para brocar, e tornear as peças» de artilharia «horizontalmente, carros rodando sobre vigas horizontaes, e levantadas acima do chaõ, por meio das quaes se tiravaõ as peças das covas" onde eram fundidas, "e se transportavam a outros lugares, de cuios inventos se approveitou Bartholomeo da Costa, para tirar, e transportar a estátua fora do Arcenal; mas intrigas entre Bartholomeo da Costa e o dito Drouet desgostaraõ este ultimo ao ponto de se retirar para Venezan.

A estátua a que Ratton se refere é a estátua equestre de D. José. no Terreiro do Paço, em Lisboa, para a qual o brigadeiro Bartolomeu da Costa procedeu à fundição, no Arsenal do Exército, do conjunto, numa só peça, do cavalo e cavaleiro, de bronze. Bartolomeu da Costa foi muito aplaudido, pelas

( $\left.{ }^{30}\right)$ Sobre Drouet e Brocard veja-se Legação de Portugal em Inglaterra, Caixa 6, ofício de 10-IV-1764, e Minist. dos Neg. Estrang. Maço 61, ofícios de 7-V e 2-VII-1764 e 14-VI-1765. Além de mestres de fundição, como os dois citados, também já se tinham mandado vir de Londres carpinteiros, ferreiros e latoeiros (Documentos da mesma Legação, Caixa 5, recibo datado de 3-IV-1762). 
dificuldades que o trabalho apresentava, assim como a retirada da peça da cova em que fora fundida e que exigiu a invenção e construção de uma máquina apropriada. E a Drouet que Ratton atribui a invenção de um dispositivo mecânico que Bartolomeu da Costa teria depois copiado para a retirada, da cova, do conjunto de bronze.

Lippe veio de novo a Portugal em Setembro de 1767 e aqui se conservou cerca de seis meses que foram ocupados em revistas às tropas. Regressou à Alemanha, presenteado com novos brindes de diamantes que $\mathrm{D}$. José lhe concedeu, e daí se ficou correspondendo connosco para dar conselhos e responder a consultas. Embora insistentemente solicitado para tornar a vir, não voltou a aceder aos pedidos, e já bastantes anos depois, em Dezembro de 1775, o marquês de Pombal, conformado com as negativas de Lippe, lhe pedia a indicação de quem deveria vir dirigir o exército português. Lippe, embora lhe indicasse, para o efeito, um nome estrangeiro, o do general inglês MacLeane, respondeu-lhe que entre os generais portugueses havia muito bem quem servisse, particularmente o marquês de Lavradio, que era então vice-rei do Brasil, ou o marquês das Minas, também conde do Prado $\left({ }^{31}\right)$.

Não será despropositado supor que tivesse existido alguma relação entre a situação criada em Portugal pelos acontecimentos que desencadearam a Guerra dos Sete Anos e a criação, por Pombal, do Colégio Real dos Nobres de Lisboa. Iniciaram-se as hostilidades em 1756, e embora não nos tivéssemos visto imediatamente envolvidos nelas, logo se teria posto a necessidade de encarar o estado operacional do nosso exército. Como as chefias militares estavam nas mãos dos nobres e não se confiava muito na sua eficácia, é de presumir que a ideia da criação daquele Colégio surgisse do reconhecimento da necessidade de se fornecer aos pequenos fidalgos uma instrução que os preparasse conscientemente para futuras actividades bélicas. Não quer isto dizer que aquela instituição tivesse sido um Colégio Militar à semelhança do modelo que Ribeiro Sanches propôs nas Cartas sobre a Educação da Moci. dade, em 1760, mas um estabelecimento escolar que fornecesse aos jovens nobres a informação científica considerada indispensável para o conhecimento da arte da guerra.

Ia, esse Colégio, iniciar entre nós o ensino oficial das Ciências, incluindo no seu currículo a Física e a Matemática, que constituíam a grande novidade pedagógica, e também as

(') Legação de Portugal em Inglaterra, Caixa 13, carta de 30-XII-1776. Lippe morreu no ano seguinte. 
línguas clássicas, o Latim e o Grego, e as línguas modernas, o Francês, o Inglês e o Italiano, além das disciplinas tradicionais como a Retórica e a Lógica, e mais a Arquitectura Militar e Civil, o Desenho, a equitação, a esgrima, etc. Seria agora necessário contratar professores para a leccionação de todas essas matérias e nomear o corpo directivo do Colégio.

Compreende-se que Pombal tivesse alguma dificuldade na escolha de mestres portugueses para o ensino, com cariz moderno, da Física e da Matemática, a qual incluía a Geometria, a Trigonometria, a Algebra, o Cálculo Integral, etc., embora isso não fosse de todo impossível. Bastará recordar, para a Física, o nome do padre Teodoro de Almeida, oratoriano, capacitadíssimo para o efeito mas sujeito ao dedo perseguidor do ministro de D. José que acabaria por obrigá-lo a fugir do país. As vistas do ministro estavam todas voltadas para o estrangeiro, não só para as disciplinas em que se encontraria menos possibilidades de escolha entre portugueses, mas também para as restantes. Como se tratava de um empreendimento cultural foi para a Itália que essas vistas se dirigiram.

Iniciaram-se as negociações pela escolha do director do Colégio, cargo para o qual, na óptica do ministro, nenhum português serviria. $O$ convite foi dirigido, em 16-XII-1760, ao erudito italiano Jacopo Facciolati, da Universidade de Pádua, para que acedesse a vir pelo menos por três anos, encarregando-se simultaneamente do ensino da Língua Latina e da Eloquência, no Colégio, com elevado salário anual $\left({ }^{32}\right)$. Facciolati não aceitou o convite alegando que os seus oitenta anos já não lhe permitiam deslocar-se para tão longe da sua pátria. Conformado com a razão da negativa, pediu-lhe Pombal que o ajudasse no seu projecto indicando-lhe dois professores, um de Física e outro de Matemática, seguramente competentes, e também italianos. Os professores escolhidos foram Michele Franzini para a Matemática e Angelo Falier para a Física, os quais, com a lentidão com que se processavam as negociações e as viagens, só chegaram a Lisboa em Janeiro de 1762.

Os Estatutos do Colégio dos Nobres foram publicados em Março de 1761, após o que o projecto parece ter caído no esquecimento. Falier esperou durante três anos e meio, em Lisboa, que o Colégio abrisse, e resolveu regressar à Itália, com os seus vencimentos pagos, como era justo. Franzini foi mais paciente e aguardou a abertura do Colégio, o que suce-

$\left.{ }^{(32}\right)$ O assunto foi estudado em pormenor no nosso estudo História da Fundação do Colégio Real dos Nobres de Lisboa, Coimbra, 1959. 
deu em Março de 1766, cinco anos depois da sua instituição e a meio de um ano escolar.

Entretanto tinham continuado as negociações para o recrutamento dos professores das diversas matérias programadas, mas quando o Colégio abriu ainda só se conseguira contratar um escasso número deles em que predominavam os estrangeiros. De Matemática eram dois os professores, Franzini, já referido, e João Ângelo Brunelli; de Língua Greza, um irlandês, Miguel Daly; de Desenho, Carlos Francisco Ponzoni; de dança, Andrea Alberti Tedesquini; e de esgrima o francês Saint-Germain. O Colégio tinha um médico e um cirurgião, ambos estrangeiros: Gualter Wade e Pedro Dufau. Para prefeito dos estudos foi escolhido o italiano Miguel Ciera. Além dos citados estrangeiros figuravam no elenco, presente na abertura do Colégio, dois professores portugueses. $\mathbf{O}$ reitor e 0 vice-reitor eram também portugueses, talvez por não ter sido possível contratar estrangeiros que aceitassem esses cargos porque, três anos depois, ao findar o prazo de vigência desses cargos estipulados na lei, foram substituídos por dois italianos: Caetano Pecci, para reitor, e Nicolau Giliberti para vice-reitor.

Quanto ao professor de Física, que viria substituir o citado Falier, só se conseguiu um já depois de inaugurado o Colégio. Foi João António Dalla Bella, que posteriormente veio a ser incorporado na Faculdade de Filosofia da Universidade de Coimbra reformada, como aliás também o foram Franzini e Ciera. Um outro professor italiano, Domingos Vandelli, de Química e História Natural, que se pretendera viesse a leccionar no Colégio, não exerceu nele o ensino mas veio a ser um dos mestres universitários de Coimbra.

Limitámo-nos a sublinhar, com a demora exigida para dar suficiente realce às situacões expostas, a intervenção dos estrangeiros na vida nacional durante a governação pombalina, intervenção solicitada com insistência ou gratamente aceita quando oferecida, que se estendeu a todas as actividades da nação, por vezes com desaproveitamento dos valores portugueses ou com sua subestimação. Muito haveria a acrescentar ao que ficou dito não só relativamente às questões públicas nacionais como também às actuações privadas do ministro de D. José como é o caso do recurso a personalidades estrangeiras, movimentadas em segredo, para alcancar um dos seus máximos objectivos políticos: a extinção da Companhia de Jesus. Estiveram em Portugal, trabalhando nesse sentido e acolhidos como excelentes colaboradores a quem eram devidas remunerações e presentes, dois estrangeiros com ac- 
tuações distintas. Um, foi o abade Platel, francês, egresso capuchinho, que viveu em Lisboa de 1760 a 1763 e se supõe ter participado na montagem da Dedução Cronológica e Analítica e no Compêndio Histórico, peças fundamentais da campanha anti-jesuítica de Pombal. O outro estrangeiro foi o impressor italiano Nicolau Pagliarini a quem o ministro de D. José ficou devendo "esplendida colaboraçaõ" no ataque à Companhia de Jesus. Pagliarini, por ter caído no desagrado do papa Clemente XIII em consequência de certo trabalho que imprimiu, foi preso em Roma. Pombal sentiu muito o revés de "aquelle honrado homem iniquam. offendido" e chamou-o para Portugal assim que o soube liberto da prisão. Em carta escrita a Aires de Sá e Melo, nosso representante em Nápoles, Pombal ordena-lhe que prepare urgentemente o embarque de Pagliarini para Lisboa, que o trate como pessoa nobre porque o rei já lhe concedeu foro de fidalgo, que lhe entregue mil moedas de 4800 réis para organizar a vida e comprar carruagem antes de embarcar, e que venha depressa para entre nós se estabelecer «solida e decorozam. ${ }^{\circ}$ ". [...] «tenho por certo" - escreve Pombal - "que elle se naõ dezagradará nem da recepção que se lhe fizer, nem do estabelecimento, que se lhe tem destinado" ( $\left.{ }^{33}\right)$.

A carta de Pombal é de 1762 mas julgamos que Pagliarini só veio para Portugal em 1768. Aqui o esperava, realmente, um estabelecimento que lhe seria destinado, talvez aquele ¿ que a carta se refere e que então estaria apenas em projecto: a Impressão Régia. Pagliarini foi nomeado director geral da Impressão Régia, essa tão necessária instituição, fundada em Dezembro de 1768, que antecedeu a Imprensa Nacional, e cuja criação é uma das obras mais válidas do conde de Oeiras. Simultaneamente também o italiano recebeu o encargo de pôr em ordem a livraria do paço real, e de organizar a do Colégio dos Nobres, encargos para que muitos portugueses estariam capacitados. Vem a propósito recordar aquele passo das memórias de José Gorani quando se refere à visita que fez, em Lisboa, a casa do marquês de Pombal, e em que foi recebido, na ante-câmara, pelo «Senhor Blancheville, francês de naçaõ e primeiro criado de quarto de Sua Excelência» ( ${ }^{34}$ ).

\footnotetext{
(") Torre do Tombo, Ministério da Justiça, maço 47, macete 4, carta de 8-I-1762.

(a) José Gorani, Portugal. A Corte e o País nos anos de 1765 a 1767, Lisboa, 1945, p. 55.
} 